\title{
Decision-making for lung resection in patients with empyema and collapsed lung due to tuberculosis
}

\author{
Guven Olgac, MD, FETCS, ${ }^{\mathrm{a}}$ Muhammet Ali Yilmaz, MD, ${ }^{\mathrm{a}}$ Mediha Gonenc Ortakoylu, MD, ${ }^{\mathrm{b}}$ and \\ Cemal Asim Kutlu, MD, FETCS ${ }^{a}$
}

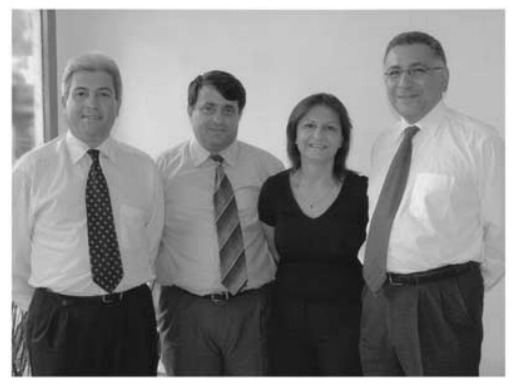

Olgac, Yilmaz, Ortakoylu, Kutlu (left to right)

Objective: Collapsed lung with associated empyema is a different clinical entity from destroyed lung. A low perfusion rate of the diseased lung is usually considered an indication for pneumonectomy in patients undergoing thoracotomy for tuberculosis. Such a criterion may not adequately reflect the functional capacity of the underlying parenchyma when the lung is collapsed.

Methods: One hundred twenty-seven patients underwent thoracotomy for tuberculosis at our hospital between 1998 and 2003. Among these, 5 (4\%) patients who had a collapsed lung for more than 3 months and pleural infection were the subjects of this study. Surgery was considered after at least a 3-month course of regular antituberculous treatment. Despite no perfusions in 2 patients and $8 \%, 10 \%$, and $15 \%$ perfusion rates for the remaining 3 patients, decortication alone was intentionally performed, and any kind of resectional operation was avoided.

Results: The lung gradually filled the hemithorax between 5 and 12 days after surgery in 4 patients. The remaining patient required a thoracomyoplasty 8 weeks after the initial operation. Repeated perfusion scans 1 and 2 years after decortication continued to show no perfusion in patients who had had no preoperative perfusion. All patients were symptom free on regular follow-up between 10 months and 4.5 years.

Conclusions: It seems that the outcome is unpredictable in terms of lung expansion after decortication, which is a relatively simple procedure compared with other surgical options. We think that the risk of rethoracotomy is acceptable, considering the devastating complications and high mortality rates of resectional surgery in the treatment of such patients.

\footnotetext{
From the Departments of Thoracic Surgery $^{\mathrm{a}}$ and Pulmonary Medicine, ${ }^{\mathrm{b}}$ Yedikule Hospital for Chest Diseases and Chest Surgery, Istanbul, Turkey.

Received for publication July 5, 2004; revisions received Aug 18, 2004; accepted for publication Aug 23, 2004.

Address for reprints: Cemal Asim Kutlu, MD, FETCS, Department of Thoracic Surgery, Hakki Yeten Cad., 17/12, Sişli 80200, Istanbul, Turkey (E-mail: cakutlu@tnn.net).

J Thorac Cardiovasc Surg 2005;130:131-5

$0022-5223 / \$ 30.00$

Copyright $\odot 2005$ by The American Association for Thoracic Surgery

doi:10.1016/j.jtcvs.2004.08.040
}

$\mathrm{M}$ ost patients with tuberculosis (TB) are treated with medical therapy, but lung resection is still indicated in a considerable number of patients and has significantly high morbidity and mortality. ${ }^{1,2}$ Empyema with parenchymal disease is an even more complicated clinical presentation in which treatment of the pleural infection is also required. Pomerant $z^{3}$ suggested pneumonectomy for patients whose remaining lung is perfused less than $15 \%$, with the assumption that the parenchyma is irreversibly damaged. Such an indication may not be adequate in some patients, particularly those who present with a collapsed lung. Some reports have also shown increased perfusion rates after decortication. ${ }^{4}$

Preservation of the lung not only facilitates control of the pleural infection, but also prevents the potential problems that would result from lung resection. Thus, regardless of its functional status, the lung should be preserved and used as a prosthesis unless parenchymal pathologic changes produce life-threatening or life-limiting problems for the patient. This study reports our experience with patients undergoing thoracotomy for collapsed lung and empyema due to TB.

\section{Patients and Methods}

We retrospectively reviewed 127 patients who underwent thoracotomy for TB at our department from 1998 to 2003. Of these, 5 patients (4\%) who presented with a collapsed lung for 
TABLE 1. Demographic and clinical details of the patients (all male)

\begin{tabular}{|c|c|c|c|c|c|c|c|c|}
\hline $\begin{array}{l}\text { Patient } \\
\text { no. }\end{array}$ & $\begin{array}{c}\text { Age } \\
\text { (y) }\end{array}$ & $\begin{array}{c}\text { Preoperative } \\
\text { diagnostic } \\
\text { method }\end{array}$ & $\begin{array}{l}\text { Perfusion } \\
\text { rate on } \\
\text { V/0 scan }\end{array}$ & $\begin{array}{c}\text { Preoperative } \\
\text { initial } \\
\text { procedure }\end{array}$ & $\begin{array}{l}\text { Preoperative anti-TB } \\
\text { treatment and duration }\end{array}$ & $\begin{array}{c}\text { Site of } \\
\text { decortication }\end{array}$ & $\begin{array}{c}\text { Duration of } \\
\text { follow-up } \\
\text { (mo) }\end{array}$ & Outcome \\
\hline 1 & 36 & SS, SC & None & CTT and OWT & $\begin{array}{l}\text { INH, RIF, MPZ, EMB, } \\
\text { SM; } 4 \text { mo }\end{array}$ & Right & 18 & Uneventful \\
\hline 2 & 21 & SC & $15 \%$ & CTT & $\begin{array}{l}\text { INH, RIF, MPZ, EMB; } \\
\quad 3 \text { mo }\end{array}$ & Left & 10 & Uneventful \\
\hline 3 & 28 & CPBx & $8 \%$ & CTT and OWT & $\begin{array}{l}\text { INH, RIF, MPZ, EMB, } \\
\text { SM; } 4 \text { mo }\end{array}$ & Left & 29 & Uneventful \\
\hline 4 & 29 & CPBx & None & CTT & $\begin{array}{l}\text { INH, RIF, MPZ, EMB; } \\
\quad 5 \text { mo }\end{array}$ & Right & 12 & Thoracomyoplasty \\
\hline 5 & 42 & SS, SC & $10 \%$ & CTT & $\begin{array}{l}\text { INH, RIF, MPZ, EMB, } \\
\text { SM; } 3 \text { mo }\end{array}$ & Left & 54 & Uneventful \\
\hline
\end{tabular}

$S S$, Sputum smear; $S C$, sputum culture; $C P B x$, closed pleural biopsy; CTT, closed tube thoracostomy; OWT, open window thoracostomy; INH, isoniazid; RIF, rifampicin; $M P Z$, morphazinamide; $E M B$, ethambutol; $S M$, streptomycin; $V / Q$, ventilation/perfusion; $T B$, tuberculosis.

more than 3 months and pleural infection were the subjects of this study. Either microbiologic or histologic diagnosis of TB was confirmed in all patients. Preoperative investigations included computed tomographic (CT) scan of the chest and arterial blood gas analysis on room air, as well as perfusion scans for evaluation of the lung parenchyma. Two patients with no perfusion also underwent magnetic resonance angiography.

Elective thoracotomy was considered after at least a 3-month course of regular anti-TB treatment, provided that the patient had made a considerable clinical improvement. Resectional surgery was intentionally avoided in all 5 patients on the assumption that any of the preoperative investigations might not have been adequately correlated with irreversible damage of the lung parenchyma. In case of postoperative expansion failure, the possibility of rethoracotomy for lung resection and/or thoracomyoplasty was also discussed with the patients, and informed consent was obtained from all.

At thoracotomy, complete pneumolysis was achieved, and a meticulous visceral decortication was performed. Major air leaks were controlled with either diathermy or suturing. Parietal decortication, single rib resection, or both were performed for better exposure in only 2 patients.

\section{Results}

Demographic data and treatment details for all patients are shown in Table 1 . Pulmonary TB was diagnosed 2 to 8 years before their last admission to our hospital in 3 patients. Only 1 completed a regular 9-month course of anti-TB treatment. None of our patients presented with recurrent chest infections or productive sputum. Furthermore, neither had any signs of bronchiectasis at their preoperative investigations. Two patients had a totally collapsed lung and associated pleural effusion (Figures $1, A$ and $B$ and 2, $A$ and $B$ ). Analysis of the pleural fluid of these 2 patients revealed an exudate. A cavitary lesion was observed in the left upper lobe of the other patient, in whom a pleural effusion developed later during his admission. His cavity completely healed with anti-TB treatment before his thoracotomy.
The diagnosis was achieved with closed pleural biopsy in 2 patients and with the presence of acid-fast bacilli on direct microscopy of the sputum, along with typical radiologic findings, in 1 patient. The other 2 patients had a pleural effusion without a previous diagnosis of TB. Direct microscopy of the sputum and pleural fluid did not reveal acid-fast bacilli. Biochemical and cytologic characteristics of pleural fluid samples were those of a transudate; therefore, a diagnosis of pleural TB could have been made only with a closed pleural biopsy in both.

In 2 of 3 patients with a history of TB, the treatment was commenced with 5 drugs according to the most recent guidelines for the management of TB. ${ }^{5}$ The treatment consisted of 4 drugs without streptomycin for the remaining 3 patients (Table 1).

The initial management of pleural fluid was simple aspiration in 2 patients and immediate chest tube insertion in another 2 patients. A chest tube was eventually inserted into all patients between the first and fifth weeks of the treatment. Because of insufficient drainage, an open-window thoracostomy was also required for 2 patients on the fourth and eighth weeks of the treatment. Removal of infected debris with twice-daily irrigations of the empyema cavity was undertaken in these patients. Subsequent cultures from the pleural fluid revealed Pseudomonas aeruginosa in 3 patients and Staphylococcus aureus in 1 patient during the course of treatment. No bacteria were isolated from the remaining patient.

Preoperative CT of the chest showed a totally collapsed lung in 3 patients, a partially expanded lung in 2 patients, and a thickened pleura in all. Perfusion scans revealed no perfusion, which was confirmed by magnetic resonance angiography, in 2 patients and showed $8 \%, 10 \%$, and $15 \%$ perfusion in the remaining patients. Preoperative $\mathrm{PO}_{2}, \mathrm{PCO}_{2}$, $\mathrm{pH}$, and oxygen saturation levels of arterial blood were within normal limits. 


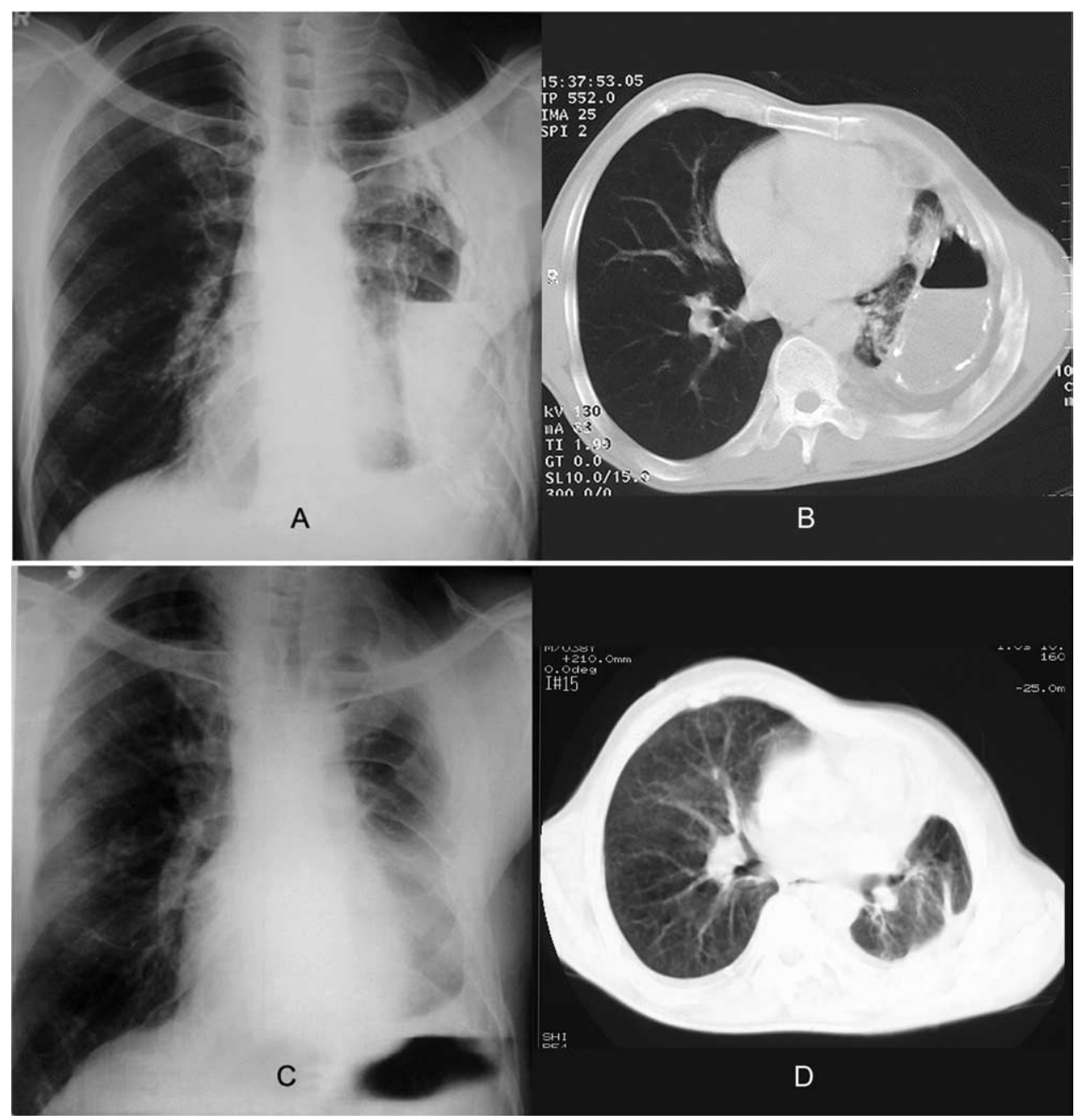

Figure 1. Preoperative and postoperative chest radiographs (A and C) and CT scans of the chest (B and D) for patient 2.

Air leak progressively decreased, and chest tubes were eventually removed within 9 to 17 days after surgery in 4 patients. Apart from prolonged air leak, there was no mortality or morbidity in these patients. However, the lung was not fully expanded despite all efforts for the remaining patient. He therefore underwent rethoracotomy and thoracomyoplasty 8 weeks after the initial operation. All patients completed a 9-month course of anti-TB treatment in total.

Patients are still being followed up on regular basis, with follow-up times of 10 months to 4.5 years, and all are free of symptoms (Figures 1, $C$ and $D$ and 2, $C$ and $D$ ). Perfusion scans were repeated at the first and second years after the operation for 2 patients in whom no perfusion was detected before surgery. Despite satisfactory outcome in the long term, these repeated scans also showed no perfusion in either patient.

\section{Discussion}

The management of TB has changed significantly over the decades. Successful treatment with drug therapy is achieved in $90 \%$ of patients. ${ }^{6}$ Some of the remaining patients may require surgery for various reasons. ${ }^{3}$ Questions arise when the indication of resection is irreversible damage of the underlying parenchyma.

Destroyed lung is the term widely used in medical literature to indicate totally damaged lung tissue after a process due to either TB or nonspecific infection. However, definition of the condition (which may be based on clinical, radiologic, or pathologic criteria) is yet to be clarified. TB is the major cause of destroyed lung (86\%), with extensive fibrosis in the lung parenchyma and bronchiectasis-like changes of the airways. ${ }^{7}$ The natural clinical course of patients with destroyed lung is usually complicated with 

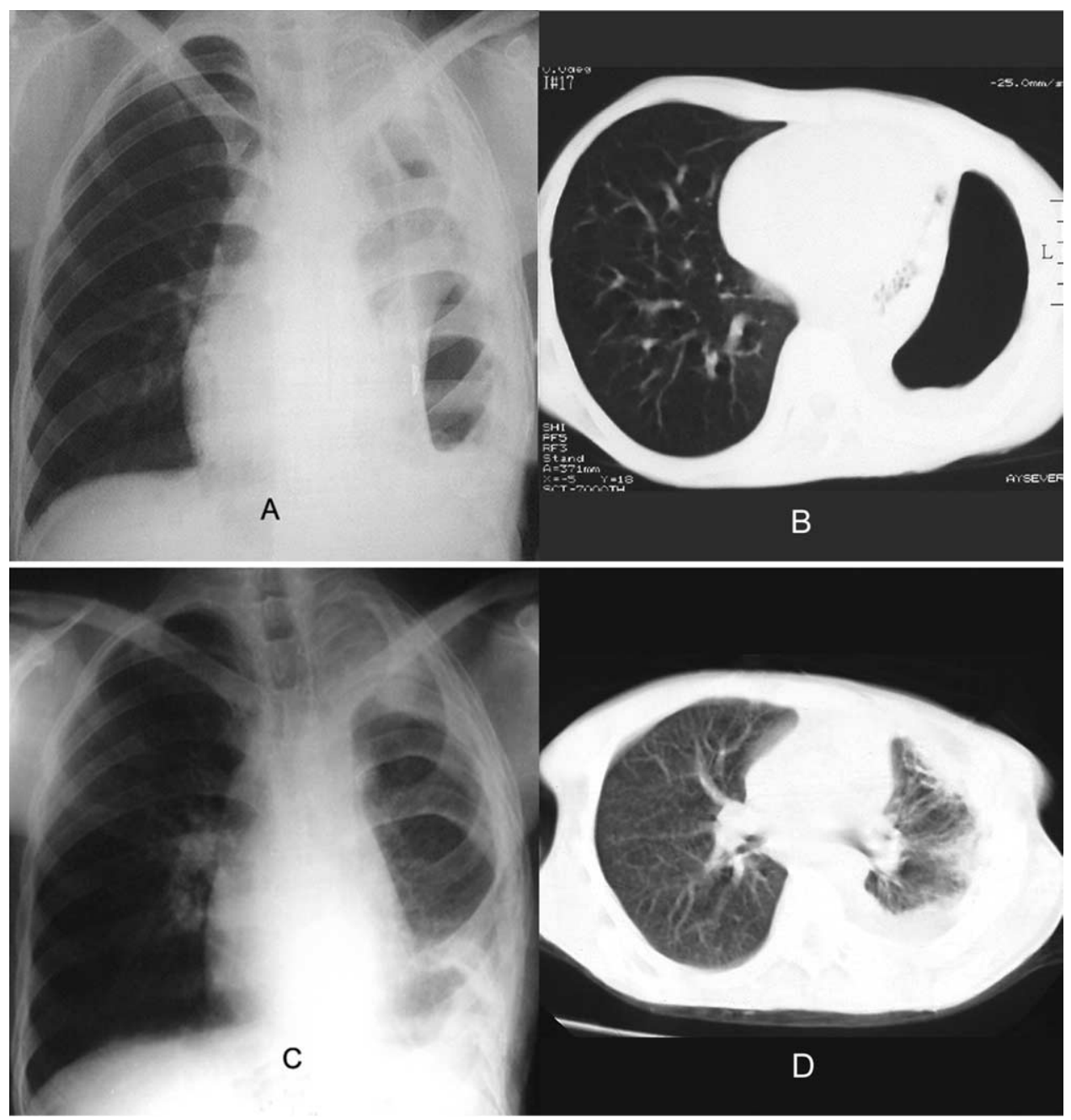

Figure 2. Preoperative and postoperative chest radiographs (A and $C$ ) and CT scans of the chest (B and D) for patient 3.

recurrent infections that lead to the formation of lung abscesses and is associated with troublesome hemoptysis. A number of pathologic processes result in parenchymal destruction during the course of TB. Regardless of the etiology, removal of the lung should be considered to prevent devastating complications.

Concomitant pleural infection results in collapsed lung because of the thickened peel on the visceral pleura. This kind of clinical presentation accounted for $13 \%$ of all patients who underwent thoracotomy in Conlan and associates' series. ${ }^{7}$ They coined the term destroyed lung and empyema for such a presentation; this term is confusing for the reader. The clinical presentation of these patients with collapsed lung and pleural infection is completely different from that of those who present with destroyed lung (Table 2).

TB is a unique infection that has various forms of progression within the lung. The functional capacity of the lung decreases as a result of fibrosis caused by parenchymal destruction followed by healing processes during the course of pulmonary TB. Although this functional loss is permanent, it does not always end with destroyed lung. Collapse therapy was the treatment of choice in the prechemotherapy era and was performed in up to $70 \%$ of all sanatorium patients. ${ }^{8}$ The purpose of this therapy was to allow scar tissue to be formed by the natural healing process. Similarly, lung collapse due to pleural infection may protect the lung from the destructive effects of TB. Patients who require resection need careful preoperative assessment of their respiratory function. Spirometry and blood gases generally remain within normal limits unless both lungs are affected. In our opinion, CT scan and other imaging techniques cannot sufficiently estimate the degree of functional loss secondary to collapsed lung. Therefore, we believe that such a definition should be regarded as morphologic rather than functional. 
A similar hypothesis may be applied to the role of perfusion scan, for the same reasons. A low perfusion rate is not necessarily an indication of functionless tissue; it may be seen in the presence of either hypoxic vasoconstriction or vasculitis caused by TB. In this situation, there are not many options for the surgeon to evaluate the damage of the lung parenchyma and predict the outcome and ability of lung to expand after decortication. Studies have reported improved lung function (22\%) and perfusion rates (38\%) after decortication in patients with nonspecific infections. ${ }^{4}$ Therefore, it is our intention to perform lung resection according to clinical presentation rather than preoperative investigations of an individual patient.

In their series of pneumonectomy for chronic infection, including TB, Massard, ${ }^{9}$ Halezeroglu, ${ }^{10}$ and their associates did not mention the role of perfusion scan as a preoperative assessment tool for resection. The main indication in both series was a clinical presentation of the disease suggesting destroyed lung. In contrast, other authors ${ }^{3,11}$ extensively used perfusion scanning in preoperative evaluation of the parenchyma. They performed pneumonectomy if the lung was perfused less than $10 \%{ }^{11}$ or $15 \% .^{3}$ However, no evidence-based data could have been provided to support this statement. We think that decreased perfusion alone is not a sufficient criterion for concluding that the lung parenchyma needs to be resected in patients with $\mathrm{TB}$, especially those who have a collapsed lung.

Our experience suggests that most of those patients can be treated by simple decortication, even with resultant limited expansion of the lung in the early postoperative period. This approach has a risk of failure, as we experienced in 1 of our patients who required rethoracotomy and thoracomyoplasty. However, any resection through the empyema cavity or pleuropneumonectomy is associated with high morbidity and mortality, even at experienced hands ${ }^{11,12}$; therefore, the risk of rethoracotomy is justified. Because of the unpredictable ability of the lung to expand in the postoperative period, we also think that neither lung resection-as Shiraishi and colleagues ${ }^{11}$ have recommended-nor concomitant procedures — such as muscle transposition, thoracoplasty, or a combination of these-are indicated in case of partial expansion after decortication.

In conclusion, there do not seem to be any reliable preoperative measures in view of decision making for lung resection in patients undergoing thoracotomy for TB. This decision is even more difficult in patients with collapsed lung and associated pleural infection. Furthermore, it seems that the outcome is somewhat unpredictable in terms of lung expansion after decortication, which is a relatively simple procedure compared with other surgical options. Therefore, we think that the risk of
TABLE 2. Differences between collapsed lung and destroyed lung

\begin{tabular}{|c|c|c|}
\hline Characteristic & Collapsed lung & Destroyed lung \\
\hline Radiologic changes & Not assessable & $\begin{array}{l}\text { Bronchiectasis, fibrosis, } \\
\text { abscess formation, } \\
\text { etc }\end{array}$ \\
\hline $\begin{array}{l}\text { Recurrent infections } \\
\text { (TB or } \\
\text { nonspecific) }\end{array}$ & Unusual & Frequent, uncontrolled \\
\hline $\begin{array}{l}\text { Endobronchial } \\
\text { abnormality }\end{array}$ & None & May be present \\
\hline Perfusion rate & None/low & Low/normal \\
\hline
\end{tabular}

$T B$, Tuberculosis.

rethoracotomy is acceptable, considering the devastating complications and high mortality rates of resectional surgery in the treatment of such patients.

We thank Drs Ilhan Vidinel and Serir Aktogu Ozkan for their contributions during the preparation of this manuscript.

\section{References}

1. Treasure RL, Seaworth BJ. Current role of surgery in Mycobacterium tuberculosis. Ann Thorac Surg. 1995;59:1405-9.

2. Reed CE, Parker EF, Crawford FA Jr. Surgical resection for complications of pulmonary tuberculosis. Ann Thorac Surg. 1989;48:165-67.

3. Pomerantz M. Surgery for the management of Mycobacterium tuberculosis and nontuberculous mycobacterial infections of the lung. In: Shields TW, LeCicero J, Ponn RB, editors. General thoracic surgery. 5th ed. Philadelphia: Lippincott Williams \& Wilkins; 2000. p.1066-75.

4. Swoboda L, Laule K, Blattmann H, Hasse J. Improving function by decortication. Functional studies with particular evaluation of lung perfusion scintigraphy. Helv Chir Acta. 1991:57;631-6.

5. American Thoracic Society/Centers for Disease Control and Prevention/Infectious Disease Society of America. Treatment of tuberculosis. Am J Respir Crit Care Med. 2003;167:603-62.

6. Centers for Disease Control and Prevention. Core curriculum on tuberculosis. Atlanta, GA: Centers for Disease Control; 1991.

7. Conlan AA, Lukanich JM, Shutz J, Hurwitz SS. Elective pneumonectomy for benign disease: modern-day mortality and morbidity. J Thorac Cardiovasc Surg. 1995;110:1118-24.

8. Steele JD. The surgical treatment of tuberculosis. Ann Thorac Surg. 1968;6:484-502.

9. Massard G, Dabbagh A, Wihlm JM, Kessler R, Barsotti P, Roeslin N, et al. Pneumonectomy for chronic infection is a high-risk procedure. Ann Thorac Surg. 1996;62:1033-8.

10. Halezeroglu S, Keles M, Uysal A, Celik M, Senol C, Keles M, et al. Factors affecting postoperative morbidity and mortality in destroyed lung. Ann Thorac Surg. 1997;64:1635-8.

11. Shiraishi Y, Nakajima Y, Koyama A, Takasuna K, Katsuragi N, Yoshida S. Morbidity and mortality after 94 extrapleural pneumonectomies for empyema. Ann Thorac Surg. 2000;70:1202-7.

12. Odell JA, Buckels NJ. Techniques of pneumonectomy: pneumonectomy through an empyema. Chest Surg Clin North Am. 1999: 9;369-78. 